\title{
Effect of montelukast added to inhaled corticosteroids on fractional exhaled nitric oxide in asthmatic children
}

\author{
L. Ghiro, S. Zanconato, O. Rampon, V. Piovan, M.F. Pasquale, E. Baraldi
}

\begin{abstract}
Effect of montelukast added to inhaled corticosteroids on fractional exhaled nitric oxide in asthmatic children. L. Ghiro, S. Zanconato, O. Rampon, V. Piovan, M. F. Pasquale, E. Baraldi. (C) ERS Journals Ltd 2002.

ABSTRACT: The aim of this prospective, self-controlled, single-blind study was to assess the effect of montelukast added to maintenance therapy with inhaled corticosteroids (ICS) on fractional exhaled nitric oxide (FENO) in asthmatic children.

Thirty-five children (age 11.2 \pm 0.4 yrs (mean \pm SEM)) with mild-to-moderate persistent asthma treated with low to medium doses of ICS and FENO $>20$ parts per billion (ppb) were included. The patients were randomly assigned to two groups: 17 patients continued ICS (group C) and 18 had montelukast added to ICS for 3 weeks (group M). FENO measurements were performed in both groups at baseline (T1) and after 3 weeks (T2), and in group M also after 2 weeks of washout. FENO was measured by a chemiluminescence analyser using an on-line method $\left(50 \mathrm{~mL} \cdot \mathrm{s}^{-1}\right)$ with nitric oxide-free air.

The overall mean daily dose of ICS was equivalent to $530 \pm 58 \mu \mathrm{g} \cdot \mathrm{day}^{-1}$ of beclomethasone in group $\mathrm{M}$ and to $564 \pm 55 \mu \mathrm{g} \cdot \mathrm{day}^{-1}$ of beclomethasone in group $\mathrm{C}$. There were no significant differences in baseline FENO and forced expiratory volume in one second (FEV1) between the two groups. After 3 weeks there was a significant reduction of FENO values in patients of group $M(T 152.2 \pm 7.8 \mathrm{ppb}, T 236.1 \pm 4.6 \mathrm{ppb})$ but no significant changes in group $C(T 143.5 \pm 6.0 \mathrm{ppb}, \mathrm{T} 247.8 \pm 9.4 \mathrm{ppb})$. In group $M$ after 2 weeks of montelukast withdrawal, FENO rose to baseline values $(55.6 \pm 8.7 \mathrm{ppb})$.

In conclusion, after montelukast treatment there is a fractional exhaled nitric oxide reduction in asthmatic children receiving maintenance therapy with inhaled corticosteroids. This suggests an anti-inflammatory effect of montelukast additive to that of inhaled corticosteroids.
\end{abstract}

Eur Respir J 2002; 20: 630-634.

Dept of Paediatrics, Unit of Allergy and Respiratory Medicine, University of Padua, Padua, Italy.

Correspondence: E. Baraldi

Dept of Paediatrics

Via Giustiniani 3

35128 Padova

Italy

Fax: 390498213502

E-mail: eugi@pediatria.unipd.it

Keywords: Airway inflammation asthma

exhaled nitric oxide

montelukast

Received: February 212002

Accepted after revision: April 122002

These data were in part presented at the annual meeting of the European Respiratory Society, Berlin, Germany, September 2001.
Fractional exhaled nitric oxide (FENO) has been proposed as a simple and noninvasive marker of airway inflammation in asthmatic patients [1]. Several studies have demonstrated that FENO in asthmatics is reduced by corticosteroid therapy $[1,2]$, and that changes in FENO due to steroid dose changes precede the improvement or worsening in asthma symptoms and lung function [1]. Recently FENO was demonstrated to be useful in predicting loss of control in asthmatic subjects when inhaled corticosteroids (ICS) were withdrawn [3], with a positive predictive value similar to that obtained using sputum eosinophils and airway hyperresponsiveness, but with the advantage that FENO is an easier-to-measure, real-time parameter. This evidence suggests that FENO measurement reflects control of asthma and may help the physician in modulating anti-inflammatory therapy [1].

The cysteinyl leukotrienes (Cys-LT) C4 and E4 play a key role in the pathophysiology of asthma [4]. The leukotriene receptor antagonists (LTRAs) that have recently been developed selectively block the binding of Cys-LT to the CysLT1 receptor, which has been identified as the receptor through which most their actions are mediated.

While there is substantial evidence of the effect of steroid treatment on FENO [1], to date few data are available on the relationship between FENO and LTRAs. Two studies have demonstrated a reduction in FENO in asthmatic children treated with montelukast regardless of concomitant treatment with ICS [5, 6], but no study has specifically addressed the effect of montelukast given as additive therapy to ICS and the effect of successive withdrawal.

The aim of this study was to assess the effect of 3-weeks treatment with montelukast added to maintenance therapy with ICS on FENO in children with mild-moderate persistent asthma. In addition, FENO was also evaluated after a 2-week post-treatment washout.

\section{Methods}

\section{Subjects}

Asthmatics. The asthmatic children were recruited from the Pulmonology/Allergy outpatient Clinic of the Department of Paediatrics of Padova, Padova, Italy. Thirty-five atopic White children (24 males, 11 females, mean age $11.2 \pm 0.4$ yrs (range $6-17$ ) with mild-moderate 
persistent asthma were enrolled. The classification of asthma was based on clinical history and examination and pulmonary function parameters, according to international guidelines [7]. All children were required to have stable asthma and to remain stable during the study period. The patients had to be on maintenance therapy with low-to-medium doses of inhaled budesonide Turbuhaler or fluticasone propionate by metereddose inhaler and spacer (equivalent to $\leqslant 800 \mu \mathrm{g} \cdot \mathrm{day}^{-1}$ of beclomethasone) [7] at a constant dose for $\geqslant 4$ weeks. As recently proposed by BISGAARD et al. [5], patients were also required to have $\mathrm{FENO}>20$ parts per billion ( $\mathrm{ppb}$ ). Long-acting $\beta_{2}$-agonist therapy was allowed during the study if it had been administered at a constant dose for $\geqslant 4$ weeks. Short-acting $\beta_{2}$-agonists were allowed as needed. No other asthma medication was allowed in the previous 4 weeks and during the study. Atopy was evaluated by skin-prick test to common allergens in the area. Patients were excluded if they had acute or chronic lung diseases other than asthma, upper or lower airway infections in the previous 3 weeks or during the trial, acute asthma exacerbation, or had used oral steroids in the last month.

Healthy controls. FENO was also measured in 26 healthy White children without a history of asthma, atopy or respiratory infections in the previous 4 weeks. None of the control subjects were taking any medication or were smokers.

\section{Study design}

This study was a prospective, self-controlled, singleblind (blind to the investigator who performed FENO measurements), randomised trial. Asthmatic children were randomised into two groups at first visit (T1): 1) group $\mathrm{M}$ : in these patients montelukast tablets $5 \mathrm{mg}$ (age $\leqslant 14 \mathrm{yrs}$ ) or $10 \mathrm{mg}$ (age $>14 \mathrm{yrs}$ ) were added to maintenance ICS therapy once daily in the evening and; 2) group C: in these patients ICS therapy was maintained and continued at a constant dose. All children were evaluated after 3 weeks (T2). Patients of group $\mathrm{M}$ were also re-evaluated 2 weeks after withdrawal of montelukast (T3). Clinical history, physical examination, FENO measurement and pulmonary function tests were performed at each visit. The Ethics Committee of the hospital reviewed and approved the protocol and all parents gave informed consent.

\section{Measurement of fractional exhaled nitric oxide}

FENO was measured with an on-line method by means of a computerised system (Aerocrine AB, Stockholm, Sweden) following the American Thoracic Society recommendations [8] as previously described [9]. Subjects inhaled nitric oxide (NO)-free air through the mouth to total lung capacity and exhaled with a target flow of $50 \mathrm{~mL} \cdot \mathrm{s}^{-1}$ against a resistor for a minimum of $6-7 \mathrm{~s}$ until a NO plateau of $\geqslant 2 \mathrm{~s}$ was achieved. No nose clip was used. FENO, expressed as ppb, was calculated as the mean of three measurements that agreed to within $10 \%$ of the mean value.

\section{Spirometry}

Pulmonary function parameters (forced expiratory volume in one second (FEV1), forced vital capacity, forced midexpiratory volume (FEF25-75)) were measured by means of a $10 \mathrm{~L}$ bell spirometer (Biomedin, Padova, Italy), and the best of three manoeuvres, expressed as a percentage of predicted values according to Polgar and Promadhat [10], was chosen. Short-acting $\beta_{2}$-agonists were withheld for $8 \mathrm{~h}$ and long-acting $\beta_{2}$-agonists for $15 \mathrm{~h}$ prior to the measurement of lung function parameters. The spirometry was performed after FENO measurement.

\section{Statistical analysis}

Data are expressed as mean \pm SEM. The comparison of FENO measurements between asthmatic children of group $\mathrm{M}$ and group $\mathrm{C}$ was carried out using the Mann-Whitney U-test. FENO, FEV1, FEF25-75 before and after 3 weeks of therapy and after 2 weeks of washout were compared with analysis of variance (ANOVA) and Scheffe's post-hoc test. Correlations between FENO and FEV1 were evaluated with the Spearman's rank correlation test. Results were considered significant at a value of $\mathrm{p}<0.05$.

\section{Results}

Eighteen asthmatic children $(\mathrm{M}=12, \mathrm{~F}=6)$ were treated with montelukast added to regular treatment with ICS (group M). Seventeen asthmatic children $(\mathrm{M}=12, \mathrm{~F}=5)$ continued regular ICS therapy at a constant dose (group C). There were no significant differences in age, disease severity, and mean dose of regular ICS between groups $\mathrm{M}$ and $\mathrm{C}$ at baseline. The overall mean daily dose of ICS was equivalent to $530 \pm 58 \mu \mathrm{g} \cdot \mathrm{day}^{-1}$ of beclomethasone in group $\mathrm{M}$ and $564 \pm 55 \mu \mathrm{g} \cdot \mathrm{day}^{-1}$ in group $\mathrm{C}(\mathrm{p}=\mathrm{NS})$. All the patients remained clinically stable throughout the study period.

Mean FENO of the whole group of asthmatics at baseline was $48.1 \pm 4.9 \mathrm{ppb}$. At $\mathrm{T} 1$ mean FENO was $52.2 \pm 7.8 \mathrm{ppb}$ in group $\mathrm{M}$ and $43.5 \pm 6 \mathrm{ppb}$ in group $\mathrm{C}$, with no significant differences between the two groups $(\mathrm{p}=\mathrm{NS})$. After 3 weeks of montelukast treatment FENO was significantly reduced by $26 \%$ in group $M(p<0.001)$, while FENO did not change in group $\mathrm{C}$ from $\mathrm{T} 1$ to $\mathrm{T} 2$ $(\mathrm{p}=\mathrm{NS})$ (table 1$)$. In group $\mathrm{M}$ the percentage of variation in FENO from $\mathrm{T} 1$ to $\mathrm{T} 2$ was not correlated to baseline FENO values $(\mathrm{r}=0.32$, $\mathrm{p}=\mathrm{NS})$. After 2 weeks of montelukast withdrawal (T3), 15 patients of group M were re-evaluated and FENO had risen to baseline value $(\mathrm{p}<0.01)$. The mean value of FENO in healthy children was $11.1 \pm 0.7 \mathrm{ppb}$.

There were no significant differences in baseline FEV1 and FEF25-75 between group $M$ and group $C$ $(\mathrm{p}=\mathrm{NS})$. There was no significant change in FEV1 between $\mathrm{T} 1$ and $\mathrm{T} 2$ in either group $\mathrm{M}(\mathrm{p}=\mathrm{NS})$ or in group $C(p=N S)$ (table 1). Similarly, $F E F 25-75$ did not change significantly between $\mathrm{T} 1$ and $\mathrm{T} 2(\mathrm{p}=\mathrm{NS})$. In the whole group of asthmatic children there was no 
Table 1. - Mean values of fractional exhaled nitric oxide (FENO), forced expiratory volume in one second (FEV1) and forced midexpiratory volume (FEF25-75) in the two study groups

\begin{tabular}{|c|c|c|c|c|c|}
\hline & \multicolumn{3}{|c|}{ Group M } & \multicolumn{2}{|c|}{ Group C } \\
\hline & $\mathrm{T} 1$ & $\mathrm{~T} 2$ & $\mathrm{~T} 3$ & $\mathrm{~T} 1$ & $\mathrm{~T} 2$ \\
\hline FENO ppb & $52.2 \pm 7.8$ & $36.1 \pm 4.6^{\#}$ & $55.6 \pm 8.7^{\bullet}$ & $43.5 \pm 6$ & $47.8 \pm 9.4^{+}$ \\
\hline FEV1 \% pred & $85.8 \pm 2.8$ & $90.1 \pm 3.4^{+}$ & $89.9 \pm 2.7^{\S}$ & $89.6 \pm 3.1$ & $91.8 \pm 3.5^{+}$ \\
\hline FEF $25-75 \%$ pred & $71.8 \pm 6.8$ & $78.6 \pm 6.5^{+}$ & $75.7 \pm 6.6^{\S}$ & $82.7 \pm 5.5$ & $85.9 \pm 5.9^{+}$ \\
\hline
\end{tabular}

Data are presented as mean \pm SEM. T1: baseline; T2: after 3 weeks; T3: after 2 weeks withdrawal; ppb: parts per billion. ${ }^{\#}:$ p $<0.001$ versus $\mathrm{T} 1 ;{ }^{\uparrow}: \mathrm{p}<0.01$ versus $\mathrm{T} 2 .{ }^{+}$: $\mathrm{p}=\mathrm{NS}$ versus $\mathrm{T} 1 ;{ }^{\S}$ : $\mathrm{p}=\mathrm{NS}$ versus $\mathrm{T} 2$. Group $\mathrm{M} \mathrm{n}=18$. Group $\mathrm{C} \mathrm{n}=17$.

correlation between FENO and FEV1 at baseline $(\mathrm{r}=-0.03, \mathrm{p}=\mathrm{NS})$.

\section{Discussion}

In this study the addition of montelukast to regular treatment with ICS for 3 weeks in asthmatic children resulted in a significant reduction in FENO. Two weeks after withdrawal of montelukast, FENO rose to baseline values.

Conversely, no changes in FENO were observed in the control group in which treatment with ICS was left unchanged (fig. 1).

These results are consistent with and extend those obtained by BISGAARD et al. [5] in a study in which a $22 \%$ reduction in FENO was observed in 11 asthmatic children when montelukast was added for 2 weeks to regular treatment with ICS. In addition, this study demonstrated a significant rebound in FENO toward pretreatment values after 2 weeks of withdrawal of montelukast, even if ICS treatment was maintained.

Leukotriene modifiers are recommended as an add-on therapy to ICS treatment in patients with moderate-to-severe asthma [7]. Recently SimONs et al. [11] showed that montelukast added to ICS therapy

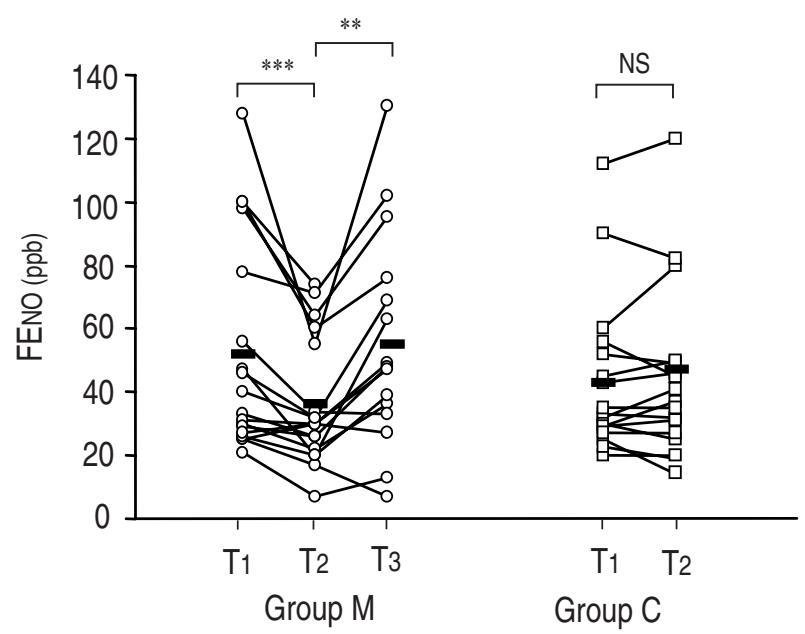

Fig. 1.- Mean and individual values of fractional exhaled nitric oxide (FENO) in the two groups. In group $\mathrm{M}$, values are reported at baseline ( $\left.\mathrm{T}_{1}\right)$, after 3 weeks of montelukast treatment $\left(\mathrm{T}_{2}\right)$ and after 2 weeks of montelukast withdrawal (T3). In group C, values are reported at baseline ( $\left.\mathrm{T}_{1}\right)$ and after 3 weeks of unchanged inhaled corticosteroid therapy (T2). ppb: parts per billion. **: p<0.01; ***: $\mathrm{p}<0.001$; NS: nonsignificant. Black bars indicate mean values. in asthmatic children significantly improved asthma control with a clinically relevant reduction in exacerbation days.

It is known that Cys-LT are involved in the inflammatory process in the lungs. They are potent constrictors of bronchial smooth muscle, increase airway mucosa vascular permeability, blood flow and bronchial secretions [12]. An important effect of Cys-LTs is their chemotactic activity for eosinophils, which are increased in the airways after inhalation of LTD4 and LTE4 [13, 14]. Blood eosinophils from children with asthma release more Cys-LT than those of controls, and levels are increased according to disease severity [15]. One of the main biological effects of LTRAs is the reduction of airway eosinophilia, as demonstrated in bronchial biopsies [16], broncoalveolar lavage (BAL) [17], sputum and blood [18].

Evidence of airway inflammation can be found even in asthmatic subjects with mild or well-controlled symptoms [19]. Indeed, the patients studied here were clinically stable but had elevated FENO levels indicative of an underlying inflammatory process. A number of studies evaluating induced sputum, BAL and bronchial biopsies have proved that FENO is associated with eosinophilic inflammation in asthmatic subjects [20] and may help in identifying patients in whom eosinophilic inflammation persists despite ICS therapy $[20,21]$. It has been demonstrated that FENO is higher in asthmatic patients compared to healthy subjects, that it is reduced by steroid therapy in a dose-dependent manner [1], and that changes in FENO due to steroid dose modifications precede the improvement or worsening in asthma symptoms, lung function and sputum eosinophils [1]. Therefore, FENO can be considered an early marker of deteriorating asthmatic disease. However, in some adult patients with severe asthma, high levels of FENO have been reported in spite of high doses of oral or inhaled steroids [22]. Recently, WiLson and LipwORTh [23] showed that in adults with mild-moderate asthma there was a significant decrease in FENO between doses of budesonide of $200 \mu \mathrm{g}$ and $400 \mu \mathrm{g}$, but a plateau was reached between doses of 400-800 $\mu \mathrm{g}$. These findings suggest that in some patients asthma may be partially insensitive to the usual doses of steroids, or that corticosteroids cannot fully control all aspects of asthmatic inflammation. In a recent study, increased levels of leukotrienes in exhaled breath condensate have been demonstrated in asthmatic patients despite receiving ICS therapy [24].

While many studies have shown the in vitro 
reduction of Cys-LT by steroids [25], in vivo baseline excretion of Cys-LT is not suppressed by corticosteroids [26]. LTE4 concentrations in BAL are not affected by high doses of oral steroids [25] and inhaled corticosteroids have no effect on urinary LTE4 excretion after allergen challenge [27]. It has been suggested that some mediators present in vivo, such as interleukin 3, modulate susceptibility to corticosteroids [28].

Even though the present study was limited by the single-blind design, the reduction observed in FENO values after montelukast treatment and the rebound following its washout period in patients on long-term treatment with ICS supports the anti-inflammatory effect of LTRAs and their complementary action to that of steroids, as recently reported by LIPWORTH et al. [29] and BISGAARD et al. [5].

The reduction in FENO observed in the patients after montelukast therapy was not associated with significant changes in pulmonary function, in agreement with previous studies in asthmatic children $[5,6]$. This can probably be explained by the baseline normal lung function (mean FEV1 86\%) of these children that precludes space for improvement, and highlights that normal lung function does not exclude the presence of underlying airway inflammation, as recently shown in bronchial biopsies of adolescent patients with asthma remission but increased levels of FENO [20].

In conclusion, this study shows that after montelukast treatment there is a reduction in fractional exhaled nitric oxide in asthmatic children receiving maintenance therapy with inhaled corticosteroids. This suggests an anti-inflammatory effect of montelukast additive to that of steroids and supports the contention that leukotriene receptor antagonists added to inhaled corticosteroids may be a useful second-line therapy that contributes to controlling airway inflammation.

\section{References}

1. Kharitonov SA, Barnes PJ. Exhaled markers of pulmonary disease. Am J Respir Crit Care Med 2001; 163: 1693-1722.

2. Baraldi E, Azzolin MN, Zanconato S, Dario C, Zacchello F. Corticosteroids decrease exhaled nitric oxide in children with acute asthma. J Pediatr 1997; 131: $381-385$

3. Jones SL, Kittelson J, Cowan JO, et al. The predictive value of exhaled nitric oxide measurements in assessing changes in asthma control. Am J Respir Crit Care Med 2001; 164: 738-743.

4. Drazen JM, Israel E, O'Byrne PM. Treatment of asthma with drugs modifying the leukotriene pathway. N Engl J Med 1999; 340: 197-206.

5. Bisgaard H, Loland L, Anhaaj J. NO in exhaled air of asthmatic children is reduced by the leukotriene receptor antagonist montelukast. Am J Respir Crit Care Med 1999; 160: 1227-1231.

6. Bratton DL, Lanz Miguel J, Mijazawa N, White CW, Silkoff PE. Exhaled nitric oxide before and after montelukast sodium therapy in school-age children with chronic asthma: a preliminary study. Pediatr Pulmonol 1999; 28: 402-407.

7. National Asthma Education and prevention program. Expert panel report 2: guidelines for the diagnosis and management of asthma. NIH Publication 97-4051, 1997. Bethesda, MD, National Heart, Lung, and Blood Institute, 1997.

8. Recommendations for standardised procedures for the on-line and off-line measurement of exhaled lower respiratory nitric oxide and nasal nitric oxide in adults and children-1999. Official statement of the American Thoracic Society. Am J Respir Crit Care Med 1999; 160: 2104-2117.

9. Baraldi E, Scollo M, Zaramella C, Zanconato S, Zacchello F. A simple flow-driven method for online measurement of exhaled NO starting at the age of 4 to 5 years. Am J Respir Crit Care Med 2000; 162: 1828-1832.

10. Polgar G, Promadhat V. Pulmonary function testing in children: techniques and standards. Philadelphia, WB Saunders, 1974.

11. Simons FE, Villa JR, Lee BW, et al. Montelukast added to budesonide in children with persistent asthma: a randomized, double-blind, crossover study. J Pediatr 2001; 138: 694-698.

12. Bisgaard H. Leukotriene modifiers in pediatric asthma management. Pediatrics 2001; 107: 381-390.

13. Latinen LA, Latinen A, Haahtelat T, Vilkka V, Spur $\mathrm{BV}$, Lee TH. Leukotriene E4 and granulocytic infiltration into asthmatic airways. Lancet 1993; 341: 989-990.

14. Diamant Z, Hilterman JT, van Rensen EL. The effect of inhaled leukotriene D4 and methacoline on sputum cell differentials in asthma. Am J Crit Care Med 1997; 155: $1247-1253$

15. Schauer U, Eckhart A, Muller R, Gemsa D, Rieger $\mathrm{CH}$. Enhanced leukotriene $\mathrm{C} 4$ production by peripheral eosinophilic granulocytes from children with asthma. Int Arch Allergy Appl Immunol 1989; 90: 201206.

16. Nakamura Y, Hoshino M, Sim JJ, Ishii K, Hosaka K, Sakamoto T. Effect of the leukotriene receptor antagonist pranlukast on cellular infiltration in the bronchial mucosa of patients with asthma. Thorax 1998; 53: 835-841.

17. Calhoun WJ, Williams KL, Simonson SG, Lavins BJ. Effect of zafirlukast (Accolate) on airway inflammation after segmental allergen challenge in patients with mild asthma. Allergy 1997; 37: 90.

18. Pizzichini E, Leff JA, Reiss TF. Montelukast reduces airway eosinophilic inflammation in asthma: a randomised, controlled trial. Eur Respir J 1999; 14: 12-18.

19. Cai Y, Carty K, Henry RL, et al. Persistence of sputum eosinophilia in children with controlled asthma when compared with healthy children. Eur Respir $J$ 1998; 11: 848-853.

20. Van Den Toorn LM, Overbeek SE, Leman K, Hoogsteden HC, de Jongste JC, Prins JB. Airway inflammation is present during clinical remission of atopic asthma. Am J Respir Crit Care Med 2001; 164: 2107-2113.

21. Payne DNR, Adcock IM, Wilson NM, Oates T, Scallan M, Bush A. Relationship between exhaled nitric oxide and mucosal eosinophilic inflammation in children with difficult asthma, after treatment with oral prednisolone. Am J Respir Crit Care Med 2001; 164: 1376-1381.

22. Stirling RG, Kharitonov SA, Campbell $\mathrm{D}$, et al. Exhaled NO is elevated in difficult asthma and correlates with symptoms and disease severity despite treatment with oral and inhaled corticosteroids. Thorax 1998; 53: 1030-1034.

23. Wilson AM, Lipworth BJ. Dose-response evaluation 
of the therapeutic index for inhaled budesonide in patients with mild-to-moderate asthma. $\mathrm{Am} \mathrm{J} \mathrm{Med}$ 2000; 108: 269-275.

24. Hanazawa T, Kharitonov SA, Barnes PJ. Increased nitrotyrosine in exhaled breath condensate of patients with asthma. Am J Respir Crit Care Med 2000; 162: 1273-1276.

25. Dworski R, Fitsgerald GA, Oayes JA, Sheller JR. Effect of oral prednisone on airway inflammatory mediators in atopic asthma. Am $J$ Respir Crit Care Med 1994; 149: 953-959.

26. Taylor GW, Taylor I, Black P. Urinary leukotriene E4 after antigen challenge and in acute asthma and allergic rhinitis. Lancet 1989; 1: 584-588.
27. O'Shaughnessy KM, Wellings R, Gillies B, Fuller RW. Differential effects of fluticasone propionate on allergen-evoked bronchoconstriction and increased urinary leukotriene E4 excretion. Am Rev Respir Dis 1993; 147: 1472-1476.

28. Crocker IC, Zhou CY, Bewtra AK, Kreutner W, Townlwy RG. Glucocorticosteroids inhibit leukotriene production. Ann Allergy Asthma Immunol 1997; 78: 497-505.

29. Lipworth BJ, Dempsey OJ, Aziz I, Wilson AM. Effects of adding a leukotriene antagonist or a longacting $\beta_{2}$-agonist in asthmatic patients with the glycine $16 \beta_{2}$-adrenoceptor genotype. Am J Med 2000; 109: $114-121$. 